\title{
Modos de vida em Assentamentos Rurais no Amazonas: Projeto de Assentamento Sustentável Paquequer - Nova Olinda do Norte (AM).
}

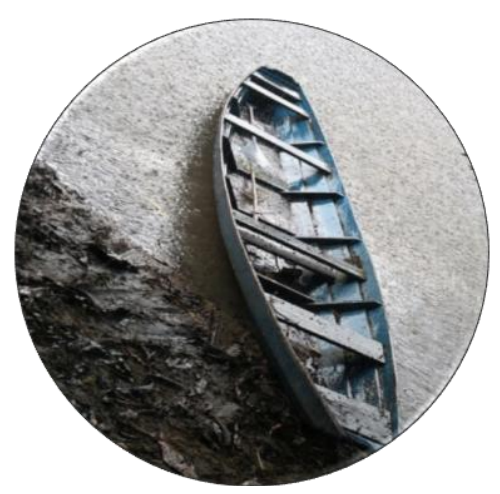

Cinthya Martins Jardim ${ }^{1}$

\begin{abstract}
Resumo
Este trabalho avalia o modo de vida em Assentamentos Rurais no Amazonas, tendo como estudo de caso, as experiências no Projeto de Assentamento Sustentável Paquequer, do município de Nova Olinda do Norte Amazonas. Estudos sobre o cotidiano dos assentados rurais na Amazônia nos permitem a criação de laços com as diversidades socioculturais encontradas nessas áreas, tornando-se fontes valiosas de conhecimento científico a partir da análise das formas de adaptação socioeconômica e das formas de adaptação ao processo de sustentabilidade vivenciado nas áreas assentadas. $\mathrm{O}$ artigo analisa a representatividade da grande maioria dos Projetos de Assentamento criados pelo INCRA na Amazônia, os quais não são frutos de reivindicações pelo MST, e sim, representam uma política adotada com o propósito de povoar o imenso vazio demográfico encontrado na região.
\end{abstract}

Palavras-chave: Amazônia. Modo de vida. Assentamentos Rurais

\begin{abstract}
This study evaluates the way of life in Rural Settlements in the Amazon, taking as a case study, the experiences lived by establishing rural in Paquequer Sustainable Settlement Project, located in the municipality of Nova Olinda do Norte - Amazonas. Studies on the daily life of rural settlers in the Amazon allow us to create links with the socio-cultural diversity found in these areas, becoming valuable sources of scientific knowledge from the analysis of the forms of socioeconomic adaptation and ways of adapting to the process of sustainability experienced in settled areas. The article analyzes the representativeness of the vast majority of Settlement Projects created by INCRA in the Amazon, which are not fruits of the MST claims, but rather represent a policy adopted with the purpose of filling the vast demographic emptiness found in this region.
\end{abstract}

Keywords: Amazon. Way of life. Rural Settlements.

\footnotetext{
${ }^{1}$ Mestre em Sociedade e Cultura na Amazônia (UFAM). cinthyajardim@ @otmail.com.
} 


\section{INTRODUÇÃO}

Ao investigar as formas de adaptação e o modo de vida das famílias que estabelecem moradias em assentamentos rurais no Amazonas, se pretende avaliar a lógica da sustentabilidade defendida e amplamente divulgada na Amazônia, tendo com estudo de caso, uma análise do modo de vida rural das famílias do Projeto de Assentamento Sustentável Paquequer, localizado no município de Nova Olinda do Norte. Este assentamento está localizado na margem esquerda da Estrada Vicinal N.O.N. - Curupira, Km 15, Gleba de Abacaxis, distando cerca de $126 \mathrm{Km}$ da capital do Estado do Amazonas.

Ao longo da história da colonização implantada na Amazônia, a presença de projetos de colonização fundiária apresentam raízes embasadas na aplicabilidade de políticas públicas de desenvolvimento centradas na questão do povoamento da região. Para Otávio Ianni (1979, p. 67), a migração espontânea para a Amazônia representava uma reforma agrária de fato, enquanto que a colonização dirigida representou a contrarreforma agrária na Amazônia. Porém, esta estrutura fundiária não abriu grandes perspectivas de acesso a terra para a maioria dos trabalhadores do campo, por possibilitar dentro da ótica capitalista, a liberação de uma fração de trabalhadores no campo que perpetuaram o processo centenário da "marcha para o oeste".

Segundo Velho (1976: 219), este processo pode ser traduzido como a marcha para as regiões mais distantes da Amazônia e que funcionaram como estratégia para atingir dois objetivos: a redução da pressão exercida pelos expropriados de regiões com acentuada concentração fundiárias e o estímulo à concentração de mais mão de obra nas regiões a serem ocupadas pelos grandes projetos na Amazônia.

O número crescente de projetos de assentamentos rurais implantados pelo Instituto Nacional de Colonização e Reforma Agrária (INCRA), no interior da Amazônia, evidenciam que a criação da grande maioria dos projetos de assentamentos nas ultimas décadas na Amazônia, não é fruto de reivindicações 
realizadas pelas lutas de classe traçadas pelo MST, e sim, representa uma política adotada pelo Governo Federal com o propósito de povoar o imenso "vazio demográfico" encontrado na região.

No caso do Assentamento Paquequer, o mesmo foi criado através da Portaria do INCRA SR (15) n $n^{\circ} 112$ de 27.11.98, publicado no Diário Oficial da União $\mathrm{n}^{\circ} 233$ de 04.12.98, originário de uma área territorial muito maior, denominada imóvel Abacaxis, é possuidor de uma área de 5.354,4117 hectares. Foi fundado oficialmente em 05 de janeiro de 1999. Esta área foi arrecadada através da Portaria INCRA/Distrito Federal - DF/N 269, de 30/11/1984 e matriculada em nome da União,

Segundo o Instituto Nacional de Pesquisa da Amazônia (INPA, 1992), a distribuição de lotes de terra na grande maioria dos assentamentos criados pelo INCRA no Amazonas, apresentam problemas com relação a questão jurídica da terra. Normalmente, os primeiros donos, em virtude da falta de infraestrutura do lugar, doam ou vendem ilegalmente as suas terras para terceiros, originando muitos processos de burocratização para legalização e liberação de nova documentação fundiária.

Em 2000, dos 132 assentados que receberam o crédito no início da instalação desse projeto, somente 113 se encontram atuando efetivamente. Atualmente, na área do assentamento se concentra cerca de 220 famílias assentadas e as dificuldades vivenciadas pelas famílias que ali se encontram estabelecidas estão relacionadas à questão da temporalidade e da espacialidade local, as quais interferem diretamente no modo de vida regional e nos mecanismos de veiculação e transporte de sua produção.

Quanto a organização e ocupação espacial encontrada no interior do Assentamento Sustentável Paquequer, os terrenos dos assentados foram loteados ao longo da lateral da estrada principal do assentamento. O modo de vida rural evidencia a forma de ocupação dos terrenos por seus moradores que acabam perpassando ao primeiro olhar, a característica de sítios rurais. As moradias são de madeira e obedecem ao modelo padrão de residências projetadas pelo INCRA 
em toda a região. São residência simples, com criação de animais domésticos de pequeno porte, árvores frutíferas e, quase sempre, nos fundos do quintal, se encontra algum tipo de produção agrícola de subsistência como o café, cacau, cupu, açaí, banana ou a roça de mandioca. Mas apenas cem famílias do assentamento foram cadastradas e recebem o acompanhamento realizados pela assistência dos técnicos do IDAM (Instituto de Desenvolvimento Sustentável do Amazonas).

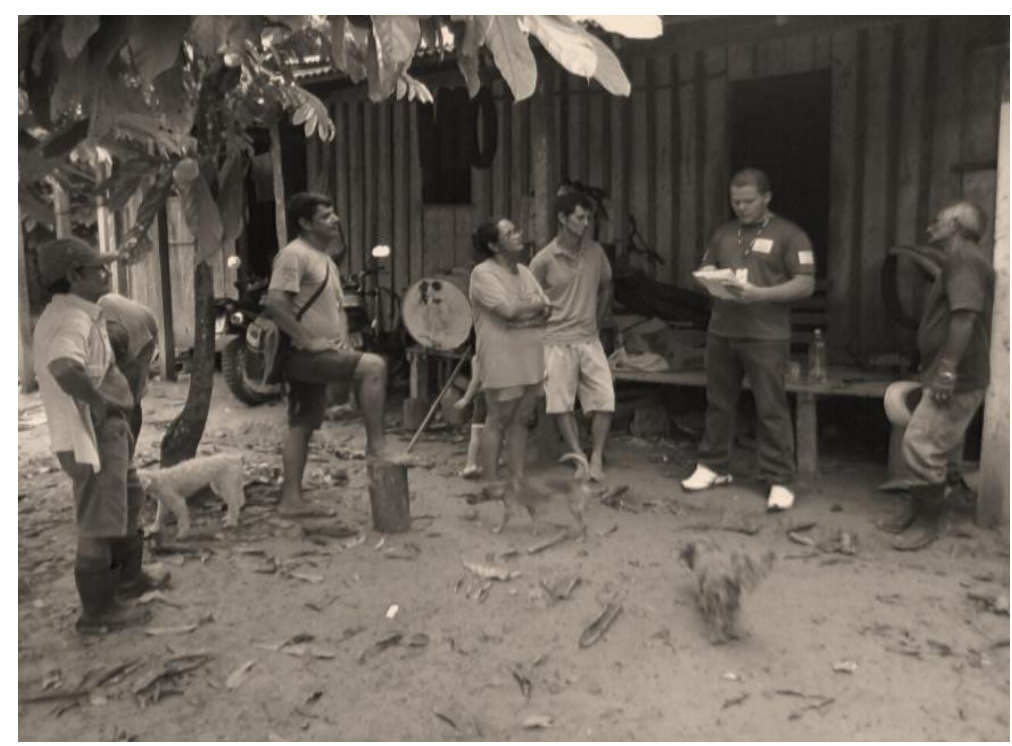

Foto 1 - Controle da vassoura de bruxa.

Fonte: Acervo IDAM, 2012.

Perceber até que ponto os recursos financeiros, a criação de infraestrutura adequada e a aplicabilidade de políticas públicas são concretas e eficazes para gerar a tão sonhada sustentabilidade ambiental no interior desse assentamento, e de que forma isto se reflete no modo de vida da população de mora no assentamento, tornaram-se as vertentes norteadoras que direcionaram a elaboração deste artigo. Quanto ao aspecto da utilização e exploração dos recursos naturais, o INCRA divulgou informações que indicam o aumento do controle ambiental nas áreas de assentamentos rurais entre 2001a 2008, quando foram expedidas 967 licenças ambientais em todo o país, representando mais de 44\% das 2.181 solicitações realizadas (INCRA, 2008). A modalidade de 
assentamento PDS - Projeto de Desenvolvimento Sustentável, vem sendo implantada pelo INCRA desde 1999, e teve seu início na região Norte do Brasil. Essa prática resultou da necessidade de estar em consonância com as novas legislações ambientais brasileiras, ao mesmo tempo que propicia o acesso a terra, à produtividade e a ocupação territorial na Amazônia.

Segundo o INCRA, o objetivo principal de criar Projetos de Desenvolvimento Sustentável, está direcionado para alcançar a durabilidade e a perpetuidade dos recursos naturais nas áreas onde estão localizados os assentamentos rurais ao longo do tempo, conjugando qualidade de vida aos seus habitantes e menores impactos ambientais na área e seus arredores. Entretanto, segundo Guerra (2006, p.78), essa nova modalidade de assentamento apresenta também certos entraves de ordem legais e naturais, pois em projetos de reforma agrária, a construção do desenvolvimento sustentável depende, basicamente, da aptidão agrícola das terras, da organização política e educacional dos assentados e da capacidade de interação com entidades governamentais e não governamentais.

É no Assentamento Paquequer que, ao longo de mais de uma década, se espera com ansiedade que se concretize a implantação de uma infraestrutura básica capaz de proporcionar acesso à saúde, educação, poços artesianos, serviços de esgoto e a terraplanagem das vias de penetração interna que deveriam ter sido oficialmente realizadas desde 2000 e que, infelizmente, até o momento, após a efetiva instalação dos assentados no projeto, ainda não foi concretizada.

\section{MATERIAL E MÉTODOS:}

O procedimento adotado para realização deste trabalho, amparou-se em articular a revisão literária junto a pesquisa empírica, abrangendo diferentes técnicas de coleta de dados coletadas em metodologia qualitativa, as quais partiram da observação participante, da história oral e de entrevistas informais realizadas junto a alguns moradores que residem a mais de cinco anos na área do assentamento. A história oral, vista como recurso complementar à documentação histórica coletada e aos dados agregados para a análise do modo de vida dos 
moradores, constituíram instrumentos estratégicos para a observação da organização social dos assentados. Brandão (1987, p.10) assevera que, à medida que o pesquisador estabelece uma relação com os sujeitos da pesquisa, a observação participante vivenciada no trabalho de campo passa a exigir sensibilidade e compromisso ético no trabalho a ser divulgado.

Nesse caso, investigar o modo de vida e as relações sociais presentes no cotidiano dos moradores do Assentamento Sustentável Paquequer gera o compromisso do pesquisador com o processo de investigação desde o projeto de elaboração dessa pesquisa. Sobre esse processo Brandão (1987, p. 12) afirma que:

Quando o outro se transforma em uma convivência, a relação obriga a que o pesquisador participe de sua vida, de sua cultura. Quando o outro me torna em um compromisso, a relação obriga a que o pesquisador participe de sua história.

A discussão teórico-conceitual, baseada em pesquisas de livros, artigos, trabalhos acadêmicos, leis e decretos, possibilitaram a abordagem da historiografia do lugar e o conhecimento da organização sociocultural e econômica dos assentados. A vertente fenomenológica será uma característica marcante neste trabalho e, esta abordagem foi possibilitada pela realização de trabalhos de campo: o primeiro em junho de 2012, no período da cheia do rio Curupira e o segundo em outubro de 2012, no período da vazante das águas na região, possibilitando a observação do modo de vida dos assentados mediante as mudanças na paisagem natural com a finalidade de captar os traços do cotidiano e os principais problemas vivenciados pelo publico alvo da pesquisa.

A base teórica que norteará este trabalho de pesquisa fundamentar-se-á na concepção materialista histórico dialética, pois a investigação se direciona para a análise do modo de vida do homem amazônico em assentamentos rurais a partir do processo de exploração que é vivenciado pelas famílias assentadas. Ao questionar o sistema de exploração que envolve essas famílias, somos impulsionados a realizar uma análise mais aprofundada da Questão Agrária no 
mundo e no Brasil, pois é importante analisar como essas políticas agrárias se refletem diretamente nas particularidades encontradas na Amazônia, tendo em vista que, sofremos influencias diretas do todo, visto que, somos partes integrantes dele.
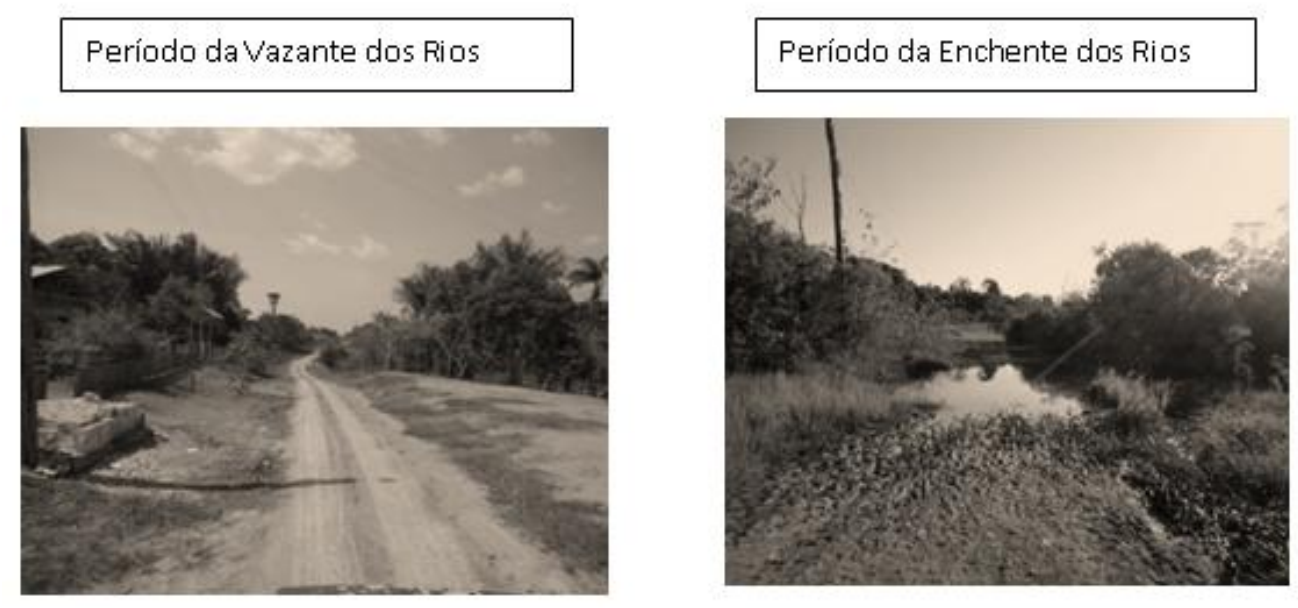

Foto 2 - Estrada do Assentamento Paquequer e as mudanças na paisagem natural do lugar.

Fonte: Cinthya Jardim, 2012.

Nesse caso, a abordagem realizada por Lênin a respeito da Questão Agrária, se torna um rico referencial teórico para suscitar questionamentos a respeito da questão agrária brasileira, induzindo a reflexões e debates sobre as lutas de classe em assentamentos rurais pautadas na questão das pressões políticas exercidas sobre os assentados, nas lutas pelos movimentos sociais e na organização de associações ou sindicatos dentro dos assentamentos. Somando-se a esse víeis, o legado teórico deixado por Kautsky, é considerado também um importante referencial a conduzir o pensamento sobre a essência dos processos que envolvem a Questão Agrária, reforçando o hábito entre os pesquisadores interessados em realizar trabalhos sobre essa temática, pois uma abordagem retornando aos pensadores clássicos, nos auxiliam para alcançar o entendimento sobre as posturas conflitantes que envolvem o real e o imaginário popular no que se refere à Questão Agrária no país. 
Com relação à empiricidade enfocada neste trabalho, as abordagens relacionadas com o cotidiano do homem rural amazônico, abrem caminhos para um diálogo capaz de desvendar novas janelas para a observação e para o estabelecimento de um olhar apurado e reflexivo que revela a essência daquilo que aparentemente se camufla no cotidiano. Nesse sentido, estudos de campo sobre a cotidianidade possibilitam avanços além da aparência daquilo que é vivido e sentido pelos seres sociais que estão atuando em um campo de lutas, para produzir e reproduzir as especificidades das relações de poder. Sobre isso Bourdieu (2012, p. 55), afirma que:

Em primeiro lugar é um espaço pré-construído: a composição social do grupo está antecipadamente determinada. Para compreender o que pode ser dito e sobretudo o que não pode ser dito no palco, é preciso conhecer as leis de formação dos grupos dos interlocutores é preciso saber quem é excluído e quem se exclui [...] os agentes em sua luta para imporem o veredito imparcial e fazerem reconhecer a sua visão como objetiva, dispõem de forças que dependem da sua pertença a campos objetivamente hierarquizados e da sua posição nos campos respectivos.

Assim, a problemática a ser investigada neste artigo dará ênfase a uma categoria de análise que estruturará as bases para a organização dos tópicos e das questões prioritárias para direcionar a interpretação do material a ser utilizado no desenvolvimento da pesquisa, pois à medida que as determinações fundamentais e secundárias deste trabalho forem sendo identificadas, será possível superar a percepção imediata da análise mecânica e empiricista, alcançando a conquista do concreto com a finalidade de expressar o conhecimento apreendido da realidade com os estudos relacionados a modo de vida e paisagem na Amazônia.

\section{FORMAS DE ADAPTAÇÃO ENTRE O RURAL E O URBANO:}

No Brasil, as primeiras iniciativas para "amenizar" os conflitos agrários no país podem ser encontradas na Constituição de 1946, afirmando que: "A lei poderá promover a justa distribuição da propriedade com igual oportunidade para todos”. Com base nessa afirmativa, a história da Reforma Agrária no país foi encontrando suporte na distribuição de lotes para agricultores sem-terra em 
assentamentos rurais. Segundo Barreto (2004, p. 82), esse processo gerou o caos jurídico fundiário no Brasil intensificado pelo contraste entre o mito e a realidade que se encontram presente no cotidiano dos assentamentos brasileiros, por isso, um estudo mais aprofundado sobre a organização e estrutura desses assentamentos, podem afirmar ao pesquisador que os mesmos são um retrato do fracasso da Reforma Agrária no Brasil.

O processo de organização do espaço fundiário do Assentamento Paquequer foi realizado pelo INCRA em 1998 na cidade de Borba, pois o município de Nova Olinda do Norte está sob a jurisdição do projeto fundiário do Médio Madeira e parte do Médio Amazonas e não possui uma política fundiária própria capaz de gestar o sistema de ocupação territorial tradicionalmente realizado em áreas de assentamento no Amazonas. Em Borba foram escolhidos os candidatos a beneficiários que seriam assentados em lotes previamente definidos. A partir daí, as atividades deste órgão se direcionou para demarcar e titular definitivamente dezesseis hectares de terra por assentado, realizando o levantamento topográfico e o mapeamento das primeiras áreas do projeto que foram divididos em 227 parcelas, com lotes de 25 a 50 hectares, conforme demonstra os dados obtidos junto ao Plano de Desenvolvimento Sustentável do P. A. Paquequer (2000, p. 38).

Em virtude desse fato, é do município de Borba que partem todas as ações que influenciaram e influenciam, direta ou indiretamente, a vida dos moradores do Assentamento Sustentável Paquequer. Logo, o primeiro obstáculo a ser vencido pelos assentados que necessitam resolver problemas relativos à legalização jurídica de suas terras, é o ato de deslocar-se até a cidade de Borba, que se distancia de Nova Olinda do Norte, cerca de cinco horas de viagem fluvial.

O estabelecimento de um estudo sobre o modelo de sustentabilidade implantado na zona rural do Amazonas requer uma analise sobre o desenvolvimento dos interesses econômicos e das ações ambientais que permeiam tal processo, em conjunto com o desenvolvimento social, cultural e econômico que se encontra presente no modo de vida da população do 
Assentamento. Paquequer. Na Amazônia, o homem e o rio são os dois mais ativos agentes da geografia humana, pois o rio é considerado o fator natural que cria tendências e estabelece o ritmo de vida das populações ribeirinhas que ali se encontram instaladas, podendo assim afirmar que nessas áreas, segundo Leandro Tocantins (2000, p.275), "o rio comanda a vida".

No entanto, ao se criar a modalidade de Assentamento Sustentável no interior da floresta Amazônica, o homem rural se vê "obrigado" a se adaptar a novas formas de veiculação e transporte. A beira do rio passa a ser substituída pela beira da estrada. Estes novos eixos de circulação, impregnados das políticas publicas e demográficas que foram implantadas na Amazônia desde a década de 70 , criam espaços de contradições e resistência, que destroem, criam e recriam as possibilidades para o estabelecimento de novas relações sociais de luta e transformação.

De acordo com Oliveira (2000, p.188), as espacialidades amazônicas aparentemente homogêneas, revelam a multiplicidade dessas ações sociais marcadas pelo modo de vida preexistente e pela adaptação às condições atuais que estão estabelecendo novos modos de vida, instituindo assim, perdas e ganhos para a (re) construção de novas espacialidades na Amazônia. Assim, a terra, o rio, o calor escaldante ou os temporais bravios, a natureza enfim tem forte conotação na vida do homem rural amazônico. É nesse ambiente natural que se estabelece o recanto de suas relações sociais e o desenrolar de todas as suas atividades. Segundo Jardim (2003, p.91), nas relações sociais encontradas nessas áreas não há graves preocupações enfrentadas pela vida urbana, pois ali se vive respeitando o tempo: o tempo das águas, o tempo da pesca, o tempo da caça, o tempo de plantar e o tempo de colher. Por isso, a questão ecológica, também não é um problema que gere graves preocupações entre os moradores das zonas rurais, pois estes se habituaram a estabelecer relações harmônicas com a terra e a água, retirando delas somente o necessário para sua subsistência. 


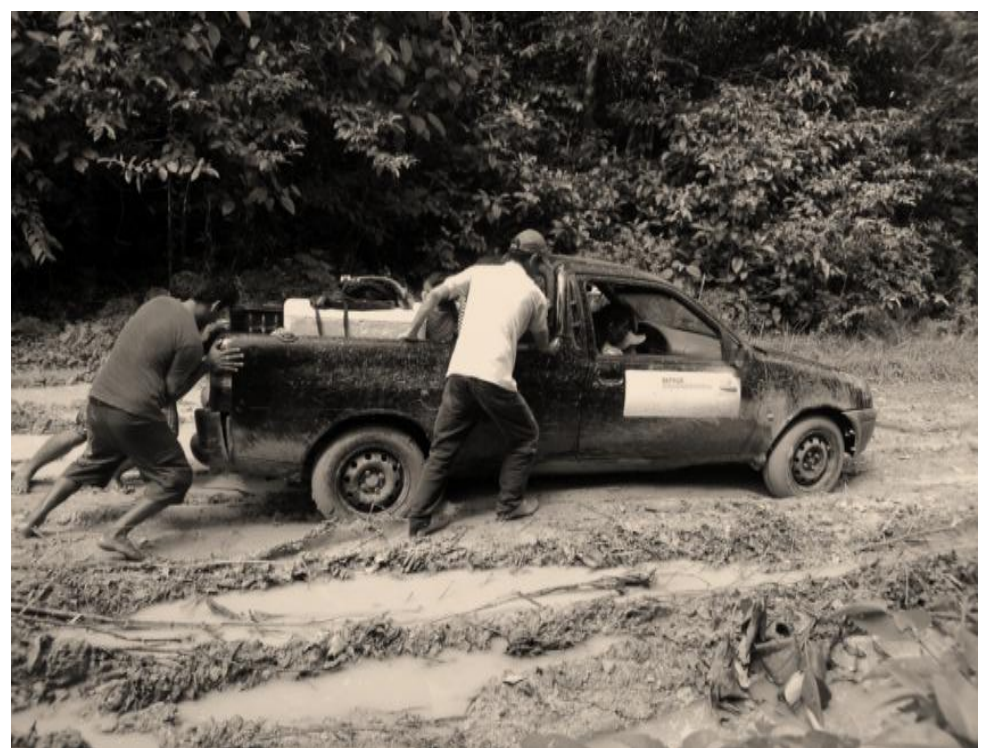

Foto 4- Estrada do P. A. Paquequer, km 10, intransitável pela ação das águas no período da enchente, isolando os assentados para o acesso a Igreja e à Escola.

Fonte: Acervo IDAM, 2012.

No Plano de Desenvolvimento Sustentável do Assentamento Paquequer (2000, p. 70-76), estavam estabelecidos projetos para a saúde, saneamento e educação. No campo educacional, previa-se construção de duas escolas rurais no assentamento no período de quatro anos, possibilitando o acesso a melhores níveis de escolaridade aos filhos dos assentados e a total fixação dessas famílias nas áreas loteadas. O plano previa uma obra dimensionada com $164 \mathrm{~m}^{2}$, de alvenaria, com vida útil prevista para 15 anos e que custaria aos cofres do Governo Federal, cerca de $\mathrm{R} \$ 54.000,00$. Porém, até o momento da realização dos trabalhos de campo no assentamento, a área de construção dessas escolas ainda não havia sido iniciada e muito menos definida.

A Secretaria de Educação Municipal de Nova Olinda do Norte, construiu na saída do Assentamento a Escola Municipal Maria Eva com estrutura de madeira que abriga cinco salas de aulas e mais um anexo. No interior do assentamento, a Secretaria Municipal de Educação, responsabiliza-se apenas por proporcionar a merenda escolar, a mão de obra, fornecendo os professores da rede municipal de ensino e um transporte escolar para os alunos que só é 
realizado na época da ausência de chuvas na região. O não fornecimento do transporte escolar das crianças na época da enchente deixa um grande numero de filhos de assentados ausentes da sala de aula. Outro agravante é que, dependendo do lote de origem, esses alunos precisam caminhar até duas horas para chegar à escola localizada dentro do assentamento, que continua funcionando em caráter precário, contando apenas com a boa disponibilidade das professoras que ali atuam.

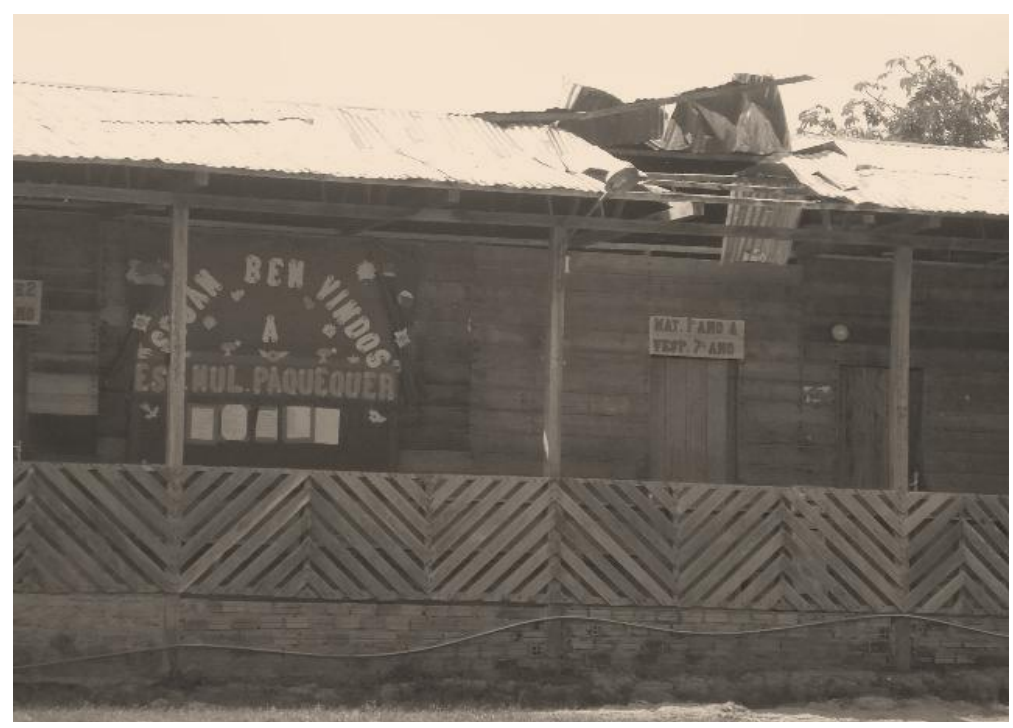

Foto 5- Escola do Assentamento Sustentável Paquequer após uma forte chuva com ventania que danificou parte da cobertura da escola Fonte: Cinthya Jardim, 2012.

Segundo Paulo Freire (2001, p. 45), ao se pensar em projetar caminhos, propor soluções ou encaminhar lutas, é desfazer a ingênua concepção que a educação pode tudo, sendo a alavanca da transformação social, pois dessa forma, equivocam-se aqueles que defendem a concepção pessimista de que o papel da educação é apenas de reprodução social, menosprezando sua função conscientizadora, crítica, criativa, transformadora e essencialmente libertadora, contribuindo para a construção e formação da cidadania.

A construção da cidadania e a luta para a construção dos espaços educativos, principalmente no meio rural, dependem muito do poder de 
organização e cooperação da população local, principalmente ao vivenciarem situações de dominação, discriminação e exploração, pois Saviani (1982, p. 67) afirma que:

Se os membros das camadas populares não dominarem os conteúdos culturais, eles não conseguirão fazer valer os seus interesses, porque ficam desarmados contra os dominadores que se servem exatamente desses conteúdos culturais para legitimar e consolidar sua dominação.

A tarefa educativa dos assentamentos rurais deve ser de responsabilidade do município, porém, sua efetivação dependerá em muitos aspectos das lideranças envolvidas no processo. É necessário relacionar e identificar o esforço que as lutas sociais realizam ao buscarem seus objetivos a partir de uma análise histórica, pois só através delas é que se percebem os avanços, as conquistas e a perseverança para não se posicionarem a margem do saber, realizando o desafio da mudança nas estruturas sociais e, especificamente, na estrutura educacional brasileira.

A luta pelos direitos sociais configura o que pode ser definido como a busca à cidadania plena. Um desses direitos e talvez a base de todos, está na educação. Pois foi através do processo educativo direcionado a sujeitos, grupos sociais ou movimentos populares que a sociedade foi se mobilizando, organizando e escrevendo a história das lutas e conquistas em nosso país.

Quanto á questão da saúde e do saneamento básico na área do assentamento, consta no Plano de Desenvolvimento Sustentável do Assentamento Paquequer (2000, p. 75-76), que deveriam ser criados no local a instalação de Posto Médico, construção de poços artesianos por lote para dotar a população de água potável necessária aos diferentes usos domésticos, construção de fossas absorventes, coleta de lixo domiciliar e a capacitação de agentes comunitários de saúde para atuar dentro do assentamento. No entanto, o único posto de saúde encontrado no assentamento é o da Fundação de Vigilância Sanitária aberto apenas quinzenalmente. Outro agravante está relacionado à 
questão da água, pois a sua aquisição é realizada junto aos igarapés ou em cacimbas localizadas próximas as residências dos assentados.

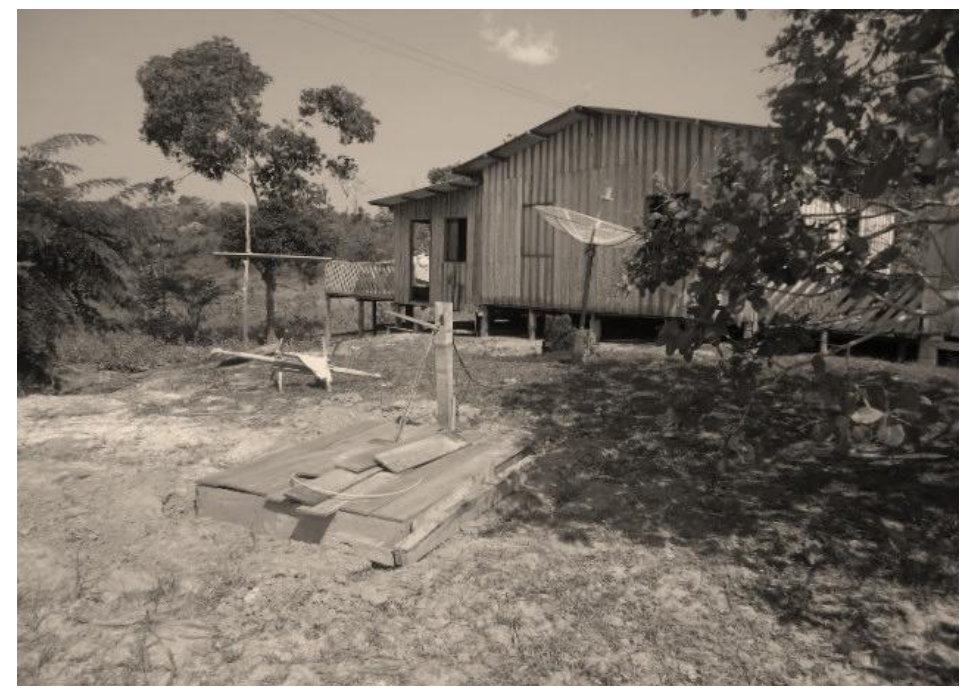

Foto 6 - Área onde foi realizada a perfuração artesanal de uma cacimba para ter acesso à água.

Fonte: Cinthya Jardim, 2012.

A problemática fundiária encontrada na zona rural do Amazonas é, sem dúvida, um desafio a ser amplamente discutido no mundo acadêmico, pois essas abordagens vão muito além da pura e simples transmissão de conhecimentos, contextualizando uma diversidade de elementos, conteúdos e fatores sociais com os quais o modo de vida rural se intercomplementam com o modo de vida urbano e o global.

Foi na história escrita pelos moradores do Assentamento Sustentável Paquequer de Nova Olinda do Norte que se organizaram os primeiros movimentos sociais estruturados no enredo de um novo modelo fundiário para o município. Essas ações, fracassos, sucessos, encontros e desencontros, constituem o lugar das lutas, dos desafios e das possibilidades de questionar a busca de novos caminhos, pois esses assentados lutam hoje, buscando a sua incorporação ao mercado e a valorização e o respeito junto àqueles que idealizaram e plantaram nos solos da Amazônia a esperança de uma cidadania inserida em um processo que não excluiria, mas que seria capaz de possibilitar ações que valorizassem e respeitassem o seu modo de vida. 
Atualmente a administração do assentamento está subordinada às decisões da maioria dos assentados no que se refere às questões de interesse comum da comunidade. Até 2009, os assentados dispunham de uma organização associativa, legalmente constituída de acordo com os registros encontrados no Livro de Ata da Associação: A APRAP (Associação dos Produtores Rurais do Assentamento Paquequer) foi criada em janeiro de 1999 e está inscrita no CNPJ sob o número 02.939.956/0001-99. No entanto, foi necessária a criação de uma nova associação devido aos problemas gerenciais vivenciados pela primeira diretoria e pela má administração das verbas do Governo Federal, as quais comprometeram em grande parte o trabalho ali iniciado.

Embora o problema tivesse sido analisado pelos órgãos gerenciadores do projeto, a APRAP ficou ao longo de dez anos temporariamente irregular até que os fatos tivessem sido legalmente apurados. Na tentativa de dar continuidade aos interesses dos associados, foi instalado em seu lugar uma Comissão Provisória, composta por um presidente, vice-presidente e membros, aos quais coube a responsabilidade de administrar corretamente os interesses dos associados. Em 20 de abril de 2010, uma nova associação foi reformulada e regulamentada, passando a se chamar Associação dos Agricultores, Agricultoras e Familiares do Projeto de Assentamento Paquequer (AFPAP).

Atualmente assume a liderança do Assentamento Paquequer e da AFPAP, a senhora Izana Santos Tavares, 37 anos. Os sonhos dessa senhora estão voltados no momento para continuar dando suporte nas ações de sustentabilidade dentro do assentamento, com a finalidade de buscar o bem estar da população assentada, muito embora não negue como é árdua a tarefa de assumir a liderança dentro do assentamento. Ela também é possuidora de um lote no assentamento juntamente com seu marido, o Sr. Alaumir Dias Gomes, que foi o primeiro presidente da Comissão de Assentados do Projeto de Assentamento Sustentável. Paquequer.

O casal possui no assentamento uma modesta casa de madeira composta por uma pequena cozinha e dois quartos. Nessa residência, a antiga sala foi 
transformada em um estabelecimento comercial para revenda de produtos básicos que o Sr. Alaumir Gomes traz da cidade, como refrigerante, biscoitos recheados, arroz, café, açúcar e outros. O casal atualmente está residindo na cidade de Nova Olinda do Norte, pela necessidade de proporcionar aos filhos acesso à escolaridade. Assim o acompanhamento e a tentativa de buscar alternativas para os problemas enfrentados pelos moradores do Assentamento Sustentável Paquequer ficou limitado à locomoção do casal, aproximadamente três vezes por semana, quando os mesmo realizam as suas visitações no assentamento.

Nessas novas espacialidades, percebe-se claramente a estreita dependência que as famílias do Assentamento Sustentável Paquequer possuem com a zona urbana do município, pois ao serem incorporados a esse processo fundiário, de fato ou juridicamente, em terras urbanas, passam a necessitar de ações planejadas em parceria com os Governos Federais e Municipais no sentido de colocarem em prática uma infraestrutura de transporte coletivo terrestre e de comunicação para proporcionar maior articulação com a zona urbana do município.

A precária infraestrutura vivenciada pelos assentados é o principal fator que compromete a permanência dos mesmos no interior do Assentamento Sustentável Paquequer. Muitos alegam que se encontram extremamente desmotivados para continuar tentando produzir no local em virtude de não receberem incentivos e nem apoio para retirar seu produto do assentamento para ir revender na cidade, pois em média, cada volume de sua produção que é transportado no ônibus particular, lhes é cobrado o valor de $\mathrm{R} \$ 5,00$. Outros alegam que a necessidade de dar continuidade à educação dos filhos e as dificuldades de acesso e transporte dentro do assentamento, principalmente na época das chuvas, os motivaram a voltar a fixar residência na zona urbana de Nova Olinda do Norte, retornando ao assentamento somente nos fins de semana.

É necessário que haja o entendimento da dinâmica social no processo de produção dessas espacialidades, ou seja, a criação desse espaço que foi 
influenciado pelas ações de sustentabilidade e preservação da natureza, produziram especificidades locais no modo de vida dos assentados, permitindo que os assentados produzam e reproduzam novas espacialidades dentro de um processo contraditório, que poderá ser classificado como o espaço das resistências (Oliveira, 2000, p.204).

Quando o homem amazônico busca a construção de novas espacialidades na zona rural, na tentativa de suprir temporariamente ou efetivamente as suas necessidades não encontradas no cotidiano urbano, nasce daí, a sua estratégia de sobrevivência frente aos seus novos desafios, induzindo-o ao campo das possibilidades entre duas realidades distintas, capazes de permitir o contato de uma com a outra, sem, no entanto, romper com a totalidade de seu cotidiano.

Com a criação das áreas de sustentabilidade nos assentamentos rurais criados pelo INCRA no Amazonas, idealizou-se simultaneamente a criação de novos hábitos culturais no trabalho e nos sistemas familiares de produção rural pela transmissão e acessibilidade de novas técnicas que se tornassem capazes de permitir melhorias nas condições socioeconômicas dos assentados, as quais viriam gradativamente a se tornar favoráveis para permitir e auxiliar a sobrevivência do pequeno produtor rural no interior do Amazonas.

Para Salazar (2004, p. 171), a mudança com o padrão de comportamento rompendo com a tradição ancestral das queimadas somente será possibilitada a partir de um esforço educativo sustentado a médio e longo prazo dentro de um esforço integrado que envolva educação de base, educação ambiental aos filhos doas agricultores, pesquisas científicas e atividade de extensão de universidades e outras instituições, visando à construção de uma consciência coletiva construtiva, pois o problema ecológico não deve ser analisado de forma desassociada do problema social e econômico encontrado nas áreas rurais da Amazônia.

Assim sendo, os estudos sobre o modo de vida observado no Assentamento Sustentável Paquequer e o seu estreito laço de dependência com o meio natural ao qual se encontra inserido, proporciona uma reflexão analítica sobre as ações ideológicas do discurso de sustentabilidade no Amazonas, 
permitindo-nos um novo posicionamento sobre o quanto essas ações estão distanciadas ou associadas aos interesses do público específico ao qual se destinam.

\section{Considerações Finais}

As preocupações do mundo contemporâneo com questões relacionadas à sustentabilidade denotam que o modelo de desenvolvimento colocado em prática na esfera global se revelou insustentável e inadequado mediante os novos desafios ambientais enfrentados pela sociedade atual.

Nas ultimas décadas é notório que a Amazônia vem recebendo muita atenção das comunidades internacionais sobre as prováveis ameaças de desequilíbrio ambiental, as quais têm influenciado diretamente no imaginário global e nas pressões políticas sobre o nosso país. Daí o discurso universal para alcançar a sustentabilidade que tem mobilizado as leis ambientais brasileiras e direcionado as ações agrárias implantadas no país.

No caso das ações realizadas pelo INCRA em ADS, a grande novidade da proposta está em vencer os desafios a partir da organização de modelos associativos e cooperativos, com a perspectiva de proporcionar voz e vez aos assentados rurais sem, no entanto, destruir as riquezas naturais da floresta. Porém, o sucesso dessa proposta depende, segundo o INCRA, da franca receptividade dos assentados para com as propostas de sustentabilidade a serem trabalhadas nos assentamentos, das parcerias e dos incentivos governamentais nas esferas Federais, Estaduais e Municipais e das condições dos meios de adaptação vivenciados por todos os assentados no local.

No caso do Assentamento Sustentável Paquequer, a falta de acompanhamento e assistência por parte desse órgão tem originado precárias condições de sobrevivência aos assentados, que acabam abandonando ou vendendo ilegalmente os seus lotes por meio de transações informais ou acelerando o processo de desmatamento em algumas áreas de assentamentos 
rurais. Outros estudos relacionados com a criação de assentamentos rurais no Amazonas, tendo como estudo de caso o Assentamento Tarumã-Mirim, segundo Coelho (2011, p. 6), também tem constatado que a situação de isolamento e abandono das famílias de assentados coordenados pelo INCRA nesses tipos de assentamento, está distanciada do critério de promover a justiça social, as melhorias da qualidade de vida e principalmente a sustentabilidade.

Viabilizar mecanismos para a implantação de um novo paradigma de sustentabilidade deverá vir a se tornar o maior desafio do Governo Federal. Daí a necessidade de se estabelecer políticas públicas ambientais articuladas com as particularidades locais encontradas na Amazônia, pois ações desarticuladas com o resto do país influenciam para o enfraquecimento do processo. Dessa forma, a busca ao sonhado desenvolvimento sustentável se torna um processo de transformação gradativa onde a exploração dos recursos, o direcionamento dos investimentos financeiros e a orientação de projetos capazes de originar o desenvolvimento tecnológico, precisam estar harmonizados e sintonizados com as metas que se desejam alcançar, sem, no entanto, comprometer o ritmo de vida da população assentada, possibilitando que as mesmas alcancem também as chances para suprir as suas necessidades básicas. Portanto, o estabelecimento da ética da sustentabilidade nas áreas de Assentamentos Sustentáveis do Amazonas requer, antes de tudo, noções e ações básicas de cidadania.

\section{Referências}

BECKER, Bertha K. Amazônia: geopolitica na virada do III milênio. Rio de Janeiro: Garamond, 2006. (Coleção Terra Mater).

BARRETO, Nelson Ramos. Reforma agrária: o mito e a realidade, histórias dos assentados, contadas por eles mesmos. São Paulo: Artpress, 2004.

BENCHIMOL, Samuel. Manual de Introdução à Amazônia. Manaus: Repográfica, 1996.

BRANDÃO, Carlos Rodrigues. Em campo aberto - escritos sobre educasaão e cultura popular. São Paulo: Cortez, 1995.

BOURDIEU, Pierre. O poder simbólico. 16. ed. Rio de Janeiro: Bertrand Brasil, 2012. 
BRASIL, Plano de Ação para a prevenção e controle do desmatamento na Amaz̧ônia Legal. 256 p., 2004.

COMISSÃO MUNDIAL SOBRE O MEIO AMBIENTE E DESENVOLVIMENTO (CMMAD). Nosso futuro comum. Rio de Janeiro: Editora FGV, 1991.

DIEGUES, Antonio Carlos. O mito moderno da natureza intocada. 2. ed. São Paulo, HUCITEC, 1998.

COELHO, O. P; Amorim, B. C. Etnoconhecimento, Organização Política e Ajuda Mútua na Comunidade Novo Amanhecer do assentamento Tarumã-Mirim (AM). In: II Simpósio Nacional de Geografia Política, Território e Poder e o I Simpósio Internacional de Geografia Política e Territórios Transfronteiriços, 2011, Foz do Iguaçu.

FREIRE, Paulo. Educação e mudança. 25. ed.Rio de Janeiro: Paz e Terra, 2001.

GUERRA, R. M. N. Discutindo a sustentabilidade nos PDS (Projeto de Desenvolvimento Sustentável): um diagnóstico do PDS São Salvador. In: Ferreira Neto, J. A. \& Doula, S. M. (Orgs.). Assentamentos Rurais e Meio Ambiente no Brasil: atores sociais, processos produtivos e legislação. UFV, 2006, cap. 5, p. 167-193.

IANNI, Octavio. Coloniz̧ação e contrarreforma agrária na Amazônia . Petrópolis: Vozes. 1979.

INSTITUTO BRASILEIRO DE COLONIZAÇÃO E REFORMA AGRÁRIA. Plano de Desenvolvimento Sustentável do Projeto de Assentamento Paquiquer do Município de Nova Olinda do Norte-Amazonas. Brasília, 2000. p. 280.

. Experiências podem levar sustentabilidade para assentamentos rurais. 22 de Maio de 2012. Disponível em: < http://www.incra.gov.br.>. Acesso em: 28 de junho de 2012.

INSTITUTO NACIONAL DE PESQUISA DA AMAZONIA. Projeto Tarumã-Mirim reúne informações em Livreto. 08 de novembro de 2008. Disponível em: < http://www.inpa.gov.br/noticias/noticia >. Acesso em: 13de junho de 2013.

JARDIM, Cinthya Martins. Espacialidade e saber: a nucleação das escolas rurais de Nova Olinda do Norte - Amaz̧onas. 2003. 194 f. Dissertação (Mestrado em Sociedade e Cultura na Amazônia) - Universidade Federal do Amazonas, Manaus, 2003.

LEITE, Sérgio (org.). Assentamentos rurais: mudança social e dinâmica regional. Rio de Janeiro: Mauad, 2004.

OLIVEIRA, José Aldemir de Oliveira. Cidades na Selva. Manaus: Valer, 2000.

PINHEIRO, A. M. Assentamentos de reforma agrária em Goiás processos de organização. Goiânia: Ed. da UFG, 1999.

ROOSEVELT, Anna C. Determinismo ecológico na interpretação do desenvolvimento social indígena na Amazônia. In: Origens, adaptação e diversidade ecológica do homem nativo da Amazônia. Belém: Museu Emílio Goeldi, 1991. 103-141.

SANTOS,M. A natureza do espaço. Técnica e tempo. Razão e emoção, São Paulo, 1996. 
SANTOS, Milton. O Espaço e a sociedade. Petrópolis: Vozes, 1989. - A natureza do espaço. 2. ed. São Paulo: HUCITEC, 1997.

SALAZAR, Adamilton Pinheiro. Amazônia: globalização e sustentabilidade. Manaus: Valer, 2004

SAVIANI, Demerval. Educação: do senso comum à consciência filosófica. São Paulo: Cortez, 1982

SPÓSITO, Ma Encarnação Beltrão e WHITACKER, Arthur Magon (org.). Cidade e campo: relacões e contradicões entre urbano e rural. São Paulo: Expressão Popular, 2010.

TELLES, Tenório (org.) e BRAGA, Celdo. Meio Ambiente: educação e qualidade de vida. Manaus: Edições Kintaw, 2004.

TOCANTINS, Leandro. O rio comanda a vida. Manaus: Valer, 2000.

TRINDADE, E. S., SCHAEFER, C. E. G. R., MUNIZ, J. N. Avaliação ambiental em áreas de assentamento de reforma agrária: o caso do PA Campo Novo, Jequitinhonha, MG. In: J. A. Ferreira Neto; S. M. Doula (orgs.), Assentamentos rurais e meio ambiente no Brasil: atores sociais, processos produtivos e legislação. Viçosa: UFV, DER, 307 p., 2006.

VELHO, Otávio Guilherme. Capitalismo Autoritário e campesinato. São Paulo, Vozes, 1979. 